\title{
Pengembangan Multimedia Interaktif Terintegrasi Nilai Sains Sebagai Solusi Peningkatan Kemampuan Berpikir Kritis Kelas XI Mata Pembelajaran Biologi Di Tingkat SMA/MA
}

\author{
Nukhbatul Bidayati Haka ${ }^{1 *}$, Putri Ayu Surya Asih' ${ }^{2)}$, Bambang Sri Anggoro ${ }^{3)}$, Abdul Hamid ${ }^{4)}$ \\ 1,2,3,4 Program Studi Pendidikan biologi, Fakultas Tarbiyah dan Keguruan, Universitas Islam Negeri \\ Raden Intan Lampung \\ Email ${ }^{*}$ : nukhbatulbidayatihaka@radenintan.ac.id
}
APA Citation: Haka, N.B., Asih P.A.S., Anggoro, B.S., Hamid, A. (2021). Pengembangan Multimedia Interaktif Terintegrasi Nilai Sains Sebagai Solusi Kemampuan Berpikir Kritis Kelas XI Mata Pembelajaran Biologi di Tingkat SMA/MA. Quagga: Jurnal Pendidikan dan Biologi, 13(1), 1-13. doi: 10.25134/quagga.v13i1.3202.

Received: 20-07-2020

Accepted: 16-10-2020

Published: 01-01-2021

\begin{abstract}
Abstrak: Pemanfaatan teknologi kurang direalisasikan padahal penggunaan media teknologi seperti multimedia interaktif android dapat menjadikan pembelajaran lebih efektif dan bermakna. Penelitian ini bertujuan untuk mengembangkan multimedia interaktif terintegrasi nilai sains yang dilihat dari segi kelayakan dan keefektifan multimedia interaktif terintegrasi nilai sains sebagai solusi peningkatan kemampuan berpikir kritis peserta didik. Metode penelitian Research and Development $(R \& D)$ Borg and Gall dengan 9 tahapan. Subjek riset meliputi tiga ahli validator yaitu ahli media, materi, dan ahli bahasa. Dan peserta didik kelas XI MIPA sebagai sampel penelitian yang terdiri dari dua kelas yaitu kelas kontrol (XI MIPA 6) dan kelas eksperimen (XI MIPA 4). Hasil data penelitian pada kelayakan produk yang terlihat dari persentasi validator yaitu ahli media sebesar 87,10\%, ahli materi sebesar 83,00\% dan ahli bahasa 83,08\% dengan kriteria "Sangat Layak" serta respon peserta didik sebesar 85,33\% yang menunjukkan kriteria "Sangat Menarik". Efektivitas dari multimedia interaktif dari hasil tes kemampuan berpikir kritis peserta didik dengan uji $t$ Independen menghasilkan thitung sebesar 7,95 dan tabel sebesar 1,70 yang artinya $t_{\text {hitung }}>t_{\text {tabel }}$ dan $H_{1}$ diterima dan hasil rata-rata nilai $N$-Gain kelas eksperimen sebesar 0,66 dan kelas kontrol sebesar 0,29. Berdasarkan hasil penelitian ini dapat disimpulkan bahwa multimedia interaktif terintegrasi nilai sains sangat layak dan efektif digunakan sebagai media pembelajaran biologi sebagai solusi peningkatan kemampuan berpikir kritis peserta didik dikelas XI MIPA Di SMA Negeri 5 Bandar Lampung. Kata Kunci: Biologi; Kemampuan berpikir kritis; Multimedia interaktif; Nilai sains.
\end{abstract}

\begin{abstract}
Utilization of technology is not realized even though the use of technological media such as android interactive multimedia can make learning more effective and effective. This study was designed to develop interactive multimedia that is integrated with the value of science seen in terms of the feasibility and effectiveness of interactive multimedia integrated with the value of science as a solution to improve students' critical thinking skills. Borg and Gall Research and Development $(R \& D)$ Method with 9 stages. The research subjects added three validator experts namely media, materials, and linguists. And students of class XI MIPA as a research sample consisting of two classes, namely the control class (XI MIPA 6) and the experimental class (XI MIPA 4). The results of research data on the feasibility of the product seen from the percentage validator were media experts at $87.10 \%$, material experts at $83.00 \%$ and linguists $83.08 \%$ with the criteria "Very Eligible" and the response of students at $85.33 \%$ which shows the "Very Attractive" criteria. The effectiveness of interactive multimedia from the students' critical ability test results with the Independent t test resulted in tcount of 7.95 and ttable of 1.70 which means tcount $>$ ttable and $H 1$ were received and the average value of the $N$-Gain value of the research class was 0, 66 and control class 0.29. Based on the results of this study it can be concluded that interactive multimedia integrated with the value of science is very feasible and effective as a medium of learning biology as a solution to improve critical thinking skills of students in the XI MIPA class of students in SMA Negeri 5 Bandar Lampung.
\end{abstract}

Keyword: Biology; Critical thinking skills; Interactive multimedia; The value of science. 


\section{PENDAHULUAN}

Istilah Revolusi Industri 4.0 dikenal dengan berkembangnya tren otomatisme yang membuat banyak perubahan dalam bidang kehidupan manusia maupun kedunia Pendidikan. Hal ini terbukti di massa pandemi saat ini penggunaan teknologi menjadi alternatif utama dalam proses pembelajaran yang dilakukan dirumah atau Daring. Masa wabah yang terjadi sekarang menimbulkan berbagai perubahan diberbagai sektor tak terkeculi di dunia pendidikan yang memiliki peranan penting dalam menghasilkan generasi yang berkualitas dalam mengembangkan inovasi kreatif dengan perubahan sifat, cara belajar, pola pikir maupun cara bertindak. Hal ini sangatlah penting diketahui oleh para pendidik dan Lembaga pendidik agar mampu mengubah model pembelajaran yang menjadikan proses belajar yang lebih interaktif yang sesuai dengan kebutuhan zaman (Hariyadi, 2019). Agar tercapainya suatu tujuan Pendidikan pendidik dituntut mampu menciptakan suasana kegiatan pembelajaran yang menyenangkan dan menarik dalam proses pembelajaran. (Sri Anggoro, 2015).

Pendidikan sains terpadu bernuansa nilainilai memiliki arti bahwa sains bukan hanya sekumpulan ilmu pengetahuan alam bahkan metode atau sikap alamiah. Pemanfaatan ilmu pengetahuan dan teknologi memberikan dampak positif maupun negative tentunya dengan adanya pembelajaran berpikir bernuansa agama, budi pekerti luhur, dan budaya bangsa yang beradap yang melekat pada setiap bidang studi, khususnya pembelajaran sains bernuansa keimanan dan ketakwaan turut menciptakan kondisi sistem pendidikan religious, edukatif, dan ilmiah (Yudianto, 2005:12). Faktanya penggunaan teknologi di sekolah belum dimanfaatkan sebagai mana mestinya sehingga media pembelajaran yang ada di sekolah kurang praktis, dan menarik dalam menunjang pembelajaran biologi, pendidik masih mengandalkan bahan ajar buku teks terlebih dalam masa wabah ini penggunaannya dirasa kurang efektif serta belum diterapkannya media pembelajaran berbasis android yang mengintegrasikan nilai sains dalam materi pembelajaran.

Penggunaan sistem multimedia dianggap penting dan memiliki banyak nilai positif bagi pendidik dan peserta didik. Multimedia interaktif merupakan suatu program yang memiliki tampilan multimedia yang dirancang untuk menginformasikan pesan dan memiliki interaktifitas kepada penggunanya diantaranya mampu menyediakan tampilan teks, gambar, video, suara, dan animasi. Proses pembelajaran penggunaan media interaktif menjadi pilihan paling efektif, sebab media ini memberikan kombinasi dari berbagai jenis media pembelajaran serta peserta didik dapat merespon langsung pada saat pembelajaran. Hasil survei dengan 128 peserta didik dimana $80 \%$ peserta atau 71 responden yang memilih pembelajaran interaktif seperti halnya email, tugas, persentasi audio serta video online dinilai sangat bermanfaat bagi pembelajaran online. (Oktavian et al. 2020) Penggunaan media menjadikan proses belajar lebih efektif, praktis serta peserta didik mudah memahami isi materi. Penggunaan media pembelajaran interaktif dapat membuat siswa lebih aktif belajar mandiri, mengasah tingkat ingatan dan lebih efesien. (Basith, 2018).

Keterampilan memecahkan masalah, keterampilan kolaborasi dan keterampilan berpikir kritis merupakan keterampilan yang harus dikuasai oleh peserta didik. (Anggoro, Haka, \& Hawanii, 2019). Kemampuan berpikir kritis merupakan runtunan perubahan pola pikir bukan hanya terhadap ingatan dan cara menyampaikan informasi melainkan dapat menggabungkan ilmu yang didapat dengan pengalaman yang telah dipahami untuk diaplikasikan dalam berpikir secara kritis maupun kreatif agar dalam memecahkan masalah yang bersifat analitis, sintesis serta evaluatif. (Manek et al, 2019). Media pembelajaran interaktif memberikan banyak fungsi bagi para pelajar yaitu dalam peningkatan pengetahuan yang kemudian dikembangkan dalam mengatasi pemasalahan yang nyata, sehingga media pembelajaran interaktif dapat menjadi solusi kemampuan berpikir siswa dalam hal kemampuan berpikir kritis dari pengetahuan yang dimiliki diimplementasi dalam pemecahan persoalan yang ada. Sehingga dalam belajar materi biologi yang cendrung abstrak dan sulit dipahami dapat mengubah pembelajaran lebih bermakna dalam meningkatkan kemampuan berpikir kritis melalui penalaran dan penerapan langsung.

Berdasarkan hal-hal diatas, maka dilakukan penelitian tentang pengembangan multimedia interaktif terintegrasi nilai sains sebagai solusi peningkatan kemampuan berpikir kritis peserta didik pada mata pembelajaran biologi. 


\section{METODOLOGI PENELITIAN}

Metode penelitian ini adalah penelitian dan pengembangan atau Research and Development (R \& D) yang mengacu pada model pengembangan Borg and Gall dengan 9 tahapan (Gambar. 1)

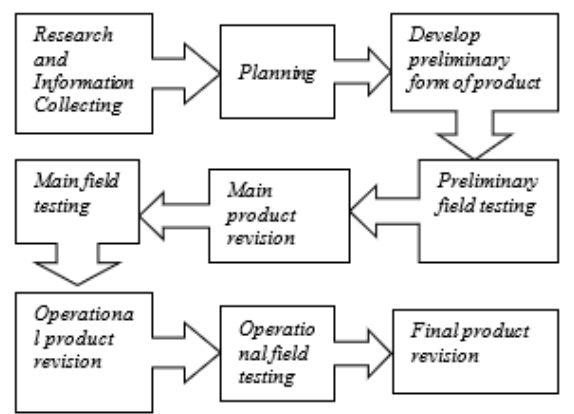

Gambar 1. $R \& D$ Borg and Gall

Tahapan pengembangan ini makin disederhanakan tetapi bukan menghilangkan sedikitpun arti nilai penelitian pengembangan yang dilakukan. (Nukhbatul bidayati Haka, \& Suhanda, 2018).

Polulasi penelitian terdiri dari seluruh anak didik kelas XI MIPA di SMAN 5 Bandar Lampung yang terdapat delapan kelas. Sampel penelitian ini menggunakan 60 peserta didik sebagai responden yang terdiri dari dua kelas yaitu kelas kontrol dan kelas eksperimen. Kelas kontrol (XI MIPA 6) 30 orang responden, sedangkan kelas eksperimen (XI MIPA 4) 30 orang responden. Teknik pengambilan sampel menggunakan Teknik acak kelas yang merupakan teknik pengambilan sampel yang diambil dari populasi tanpa memperhantikan stratanya (tingkat kepintaran).

Instrumen yang digunakan dalam penelitian dan pengembangan ini: 1). Angket validasi ahli yaitu ahli media, ahli materi dan ahli bahasa. 2). Angket respon peserta didik. 3). Tes KBK menggunakan sebanyak 20 butir soal dengan tipe multiple choice, dan 4). Dokumentasi.

Teknik analisis data dalam penelitian dan pengembangan ini ialah dengan menganalisis angket yang telah disebar diantaranya: 1). Angket Kuesioner Validasi Ahli, 2). Angket Kuesioner Respon Peserta Didik. Pengolahan kuesioner ini memakai Skala Likert untuk mengetahui analisis kuantitatif yang dapat dilihat pada Tabel I dan hasil perhitungan penilain dilihat menggunakan kriteria kelayakan produk pada Tabel 2.
Tabel 1. Skala Likert

\begin{tabular}{cccc}
\hline No & $\begin{array}{c}\text { Analisis } \\
\text { Kuantitatif }\end{array}$ & \multicolumn{2}{c}{ Skor } \\
\cline { 3 - 4 } & Positif & Negatif \\
\hline 1. & Sangat Baik (SB) & 4 & 1 \\
\hline 2. & Baik (B) & 3 & 2 \\
\hline 3. & Kurang Baik (KB) & 2 & 3 \\
\hline \multirow{3}{*}{ 4. } & $\begin{array}{c}\text { Sangat Kurang Baik } \\
\text { (SKB) }\end{array}$ & 1 & 4 \\
& & &
\end{tabular}

Tingkat pengukuran menggunakan interval dengan menilai persentase jawaban angket pada setiap item dengan rumus:

$$
\mathrm{Pi}=\frac{S}{N} \mathrm{X} 100 \%
$$

Keterangan:

Pi: Persentase ideal

S: Jumlah jawaban responden dalam 1 item $\mathrm{N}$ : Jumlah nilai ideal dalam item

Penilaian pada skor rata-rata persentase angket dengan rumus:

$$
\mathbf{P}=\frac{\sum \mathbf{P}}{\mathbf{n}} \times 100 \%
$$

Keterangan:

P: Persentase rata-rata

$\sum \mathrm{P}:$ Jumlah persentase

$\mathrm{n}$ : Jumlah item pada angket

Tabel 2. Kriteria Kelayakan

\begin{tabular}{cc}
\hline Penyataan & Skor rata-rata \% \\
\hline $\begin{array}{c}\text { Sangat Kurang } \\
\text { Layak }\end{array}$ & $\mathrm{KK} \leq 20 \%$ \\
\hline Kurang Layak & $21 \%<\mathrm{KK} \leq 40 \%$ \\
\hline Cukup Layak & $41 \%<\mathrm{KK} \leq 60 \%$ \\
\hline Layak & $61 \%<\mathrm{KK} \leq 80 \%$ \\
\hline Sangat Layak & $81 \%<\mathrm{KK} \leq 100 \%$ \\
\hline
\end{tabular}

Tes Kemampuan Berpikir Kritis. Menurut (Sundayana, 2014), hasil peserta didik mengerjakan soal selajutnya dianalisis dengan rumus $N$-Gain pada Tabel 3 digunakan untuk melihat keefektivitasan prodct.

\section{$N$-Gain $=\underline{\text { skor } \text { posttest }- \text { skor } \text { pretest }}$ skor maksimum - skor pretest}

Tingkat perolehan $\mathrm{N}$-Gain skor dikategorikan dalam tiga kategori yakni tinggi, sedang dan rendah yang dijabarkan pada Tabel 3 . 
Tabel 3. Kategori Nilai $N$-Gain

\begin{tabular}{cc}
\hline Nilai $\mathbf{N}$-Gain & Kategori \\
\hline $\mathrm{g}>\mathbf{0 , 7}$ & Tinggi \\
\hline $\mathbf{0 , 3} \leq \mathrm{g} \leq \mathbf{0 , 7}$ & Sedang \\
\hline $\mathrm{g}<\mathbf{0 , 3}$ & Rendah \\
\hline
\end{tabular}

Dalam penjabaran kategori perolehan $\mathrm{N}$-Gain dalam persen (\%) merujuk pada Tabel 4.

Tabel 4. Kategori Efektivitas Nilai N-Gain

\begin{tabular}{cc}
\hline Persentase & Kategori \\
\hline $\mathbf{g}<\mathbf{4 0} \%$ & Tidak Efektif \\
\hline $\mathbf{4 0} \%<\mathbf{g} \leq \mathbf{5 5} \%$ & Kurang Efektif \\
\hline $\mathbf{5 6} \%<\mathbf{g} \leq \mathbf{7 5} \%$ & Cukup Efektif \\
\hline $\mathbf{g}>\mathbf{7 6} \%$ & Efektif \\
\hline
\end{tabular}

\section{HASIL DAN PEMBAHASAN}

Hasil penelitian dan pengembangan pada multimedia interaktif terintegrasi nilai sains ini menggunakan sembilan tahapan yang dimulai dari studi pendahuluan guna mencari informasi sebelum dilakukannya pengembangan produk. Hasil dari dilakukannya wawancara pendidik dapat diterangkan bahwa: (a). Seluruh responden telah memiliki smartphone dan aktif namun belum digunakan fungsinya sebagai media dalam proses belajar. (b). Kurang variasi seperti bahan ajar yang berupa buku cetak, lembar diskusi, lembar kerja praktikum, majalah ilmiah dan koran. Sama halnya media pembelajaran menggunakan gambar dinding, torso, charta serta power point. (c). Materi yang disampaikan belum mengintegrasikan nilai-nilai sains. (d). Sarana pendukung seperti Wi-Fi sebagai sarana sudah tersedia di lingkungan sekolah. (e). Responden tertarik terhadap suatu media berbasis smartphone.

Tahapan kedua yaitu perencanaan yang dilakukan pada bagian media, materi dan bahasa. Proses perencanaan diawali dengan penyesuaian jenis penulisan, gambar dan video, serta bagian isi lain yang digunakan dalam produk. Perencanaan materi yang dilakukan dengan menyesuaikan kebutuhan materi yang ada disekolah dan disesuaikan dengan Kompetensi Inti dan Kompetensi Dasar yang digunakan. Perencanaan bahasa dilakukan agar penggunaan bahasa yang sesuai dengan EYD dan pengunaan aturan kata bahasa Indonesia yang tepat.

Tahapan ketiga yaitu pengembangan desain yang menggunakan software adobe flash cs6 dengan berbantuan software lain seperti corell draw x6, photoshop cc 2017 dan adobe animate 2016. Aplikasi multimedia interaktif yang dikemas dalam basis android yang memuat materi yang telah disesuaikan dengan KI, KD dan penjelasan materi yang dilengkapi gambar dan video pembelajaran sehingga dapat menambah kemampuan berpikir kritis yang dituangkan dalam menu sajian yang mudah dipilih diantaranya tampilan awal produk, materi sistem peredaran manusia yang dilengkapi video dan gambar, info biologi, praktikum virtual, evaluasi, glosarium, daftar pustaka, dan profil pengembang. Gambaran sajian produk sebagai berikut:

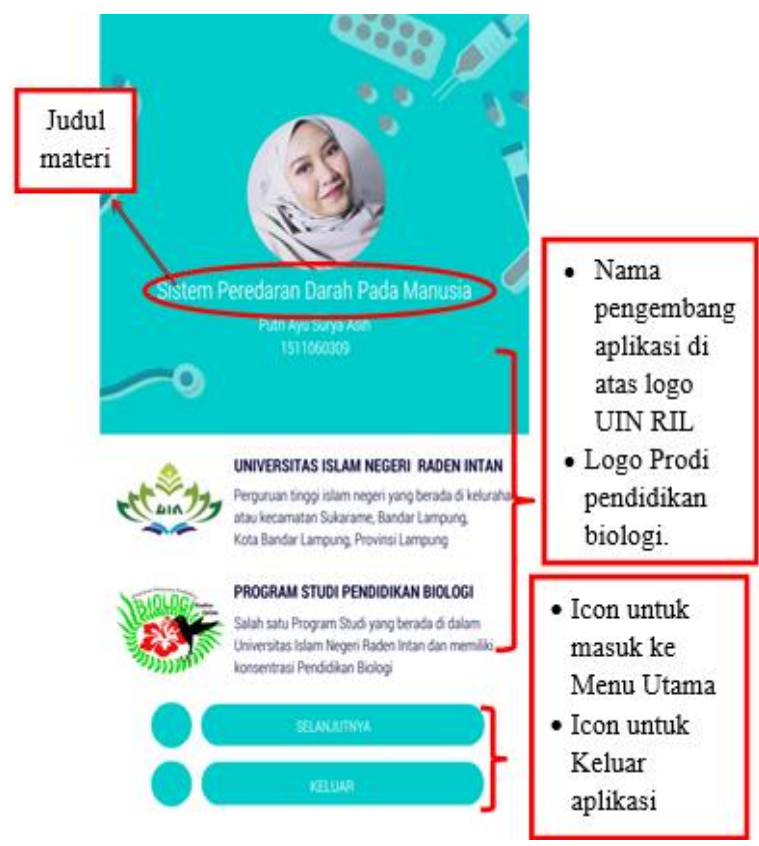

Gambar 2. Tampilan Depan

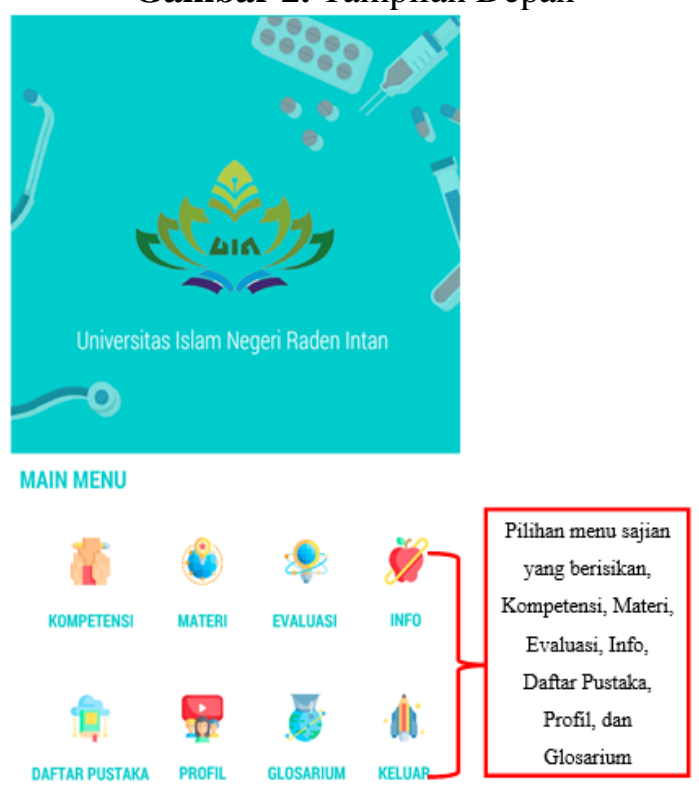

Gambar 3. Main menu 


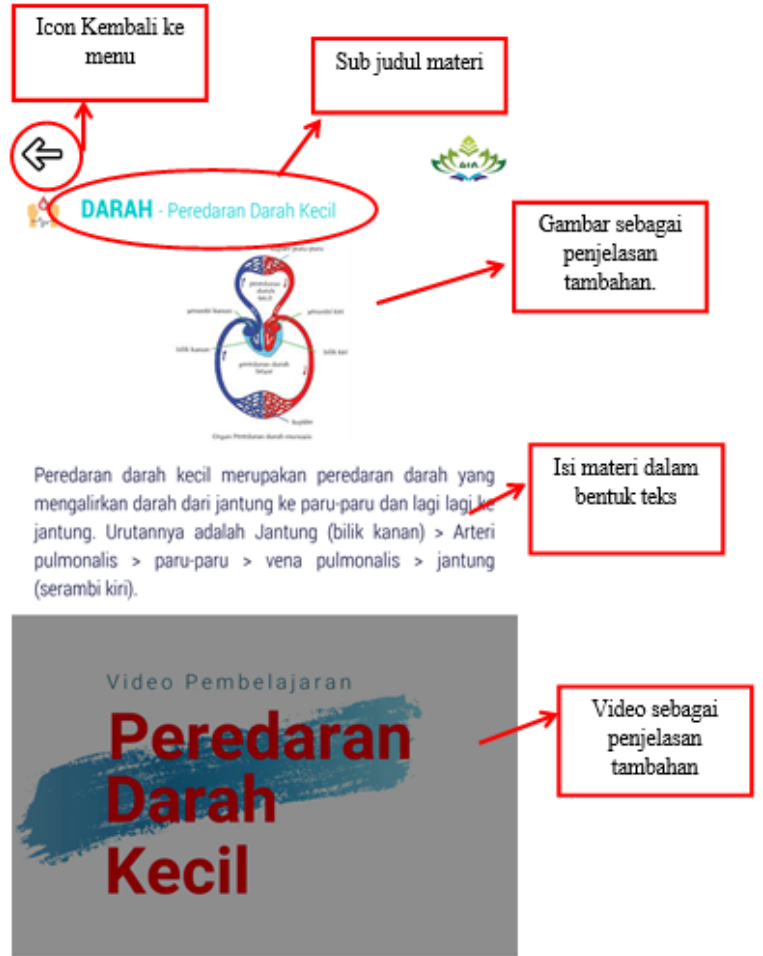

Gambar 4. Menu Sub Materi

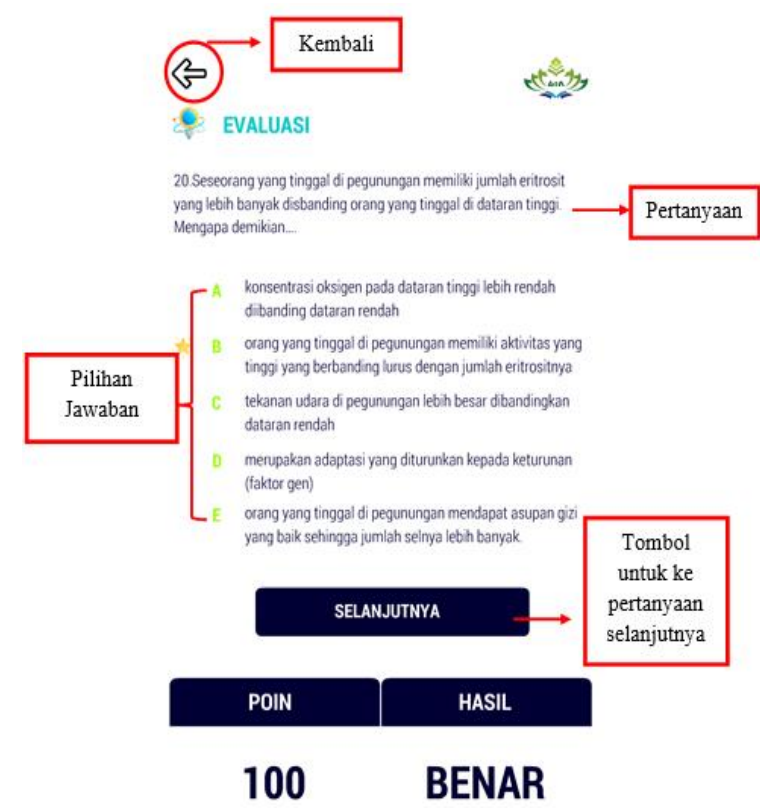

Gambar 5. Menu Evaluasi

Tahapan keempat yaitu uji coba pendahuluan adalah melakukan validasi terhadap produk yang dikembangkan guna melakukan penilaian rancangan produk awal. Tahap ini melibatkan beberapa ahli yakni 3 validator ahli media yang menghasilkan hasil pada Gambar 9. 2 validator materi Gambar 10. Validator bahasa pada Gambar 11.

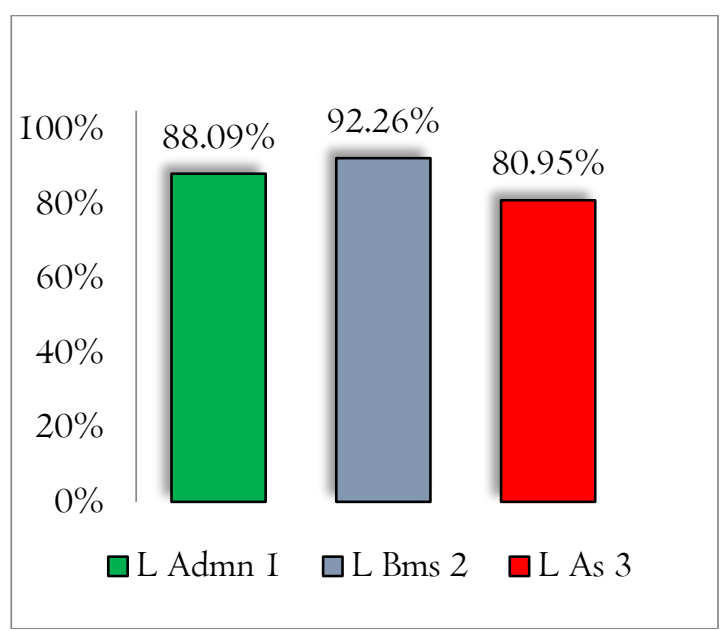

Gambar 10. Hasil Penilaian Angket Ahli Media

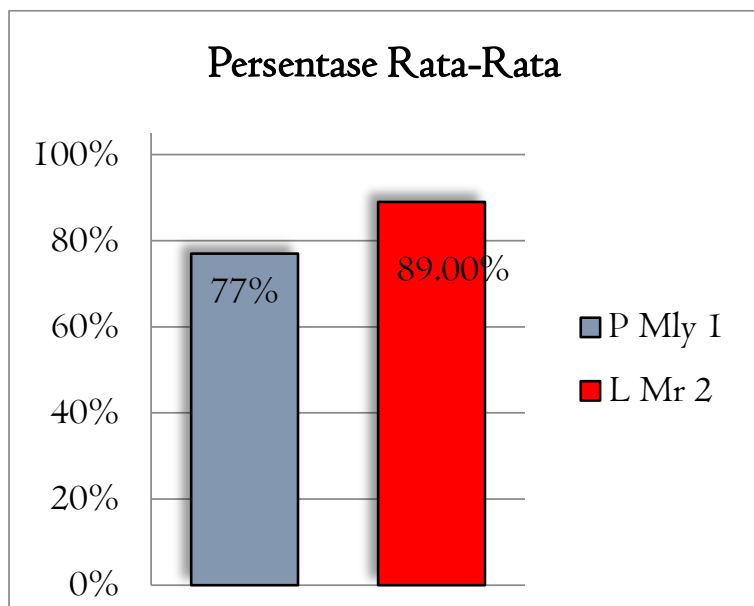

Gambar 11. Hasil Penilaian Angket Ahli Materi

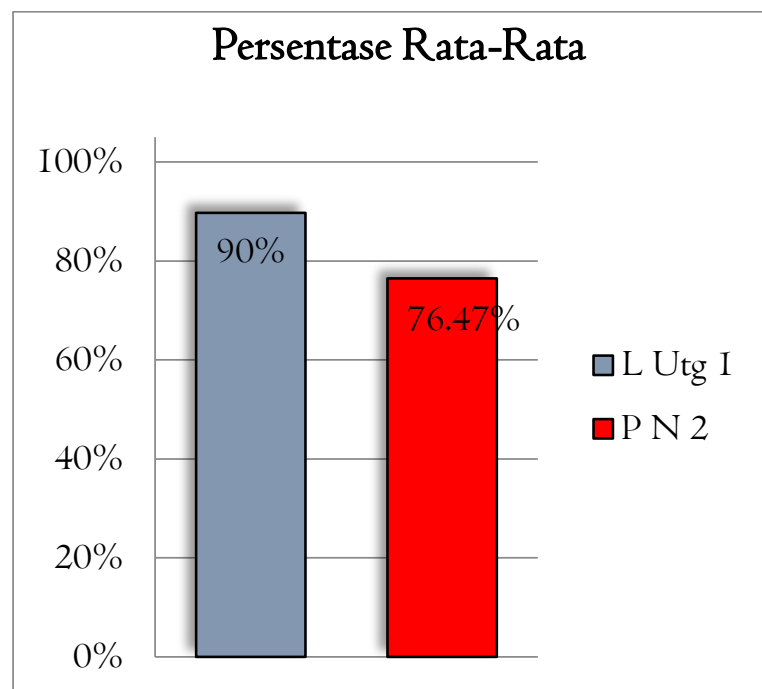

Gambar 12. Hasil Penilaian Angket Ahli Bahasa 
Setelah dilakukannya revisi produk dan telah disempurnakan sesuai masukkan beberapa validator ahli media (Tabel 5), ahli materi (Tabel 6), ahli bahasa (Tabel 7).

Tabel 5. Revisi oleh Validator Media

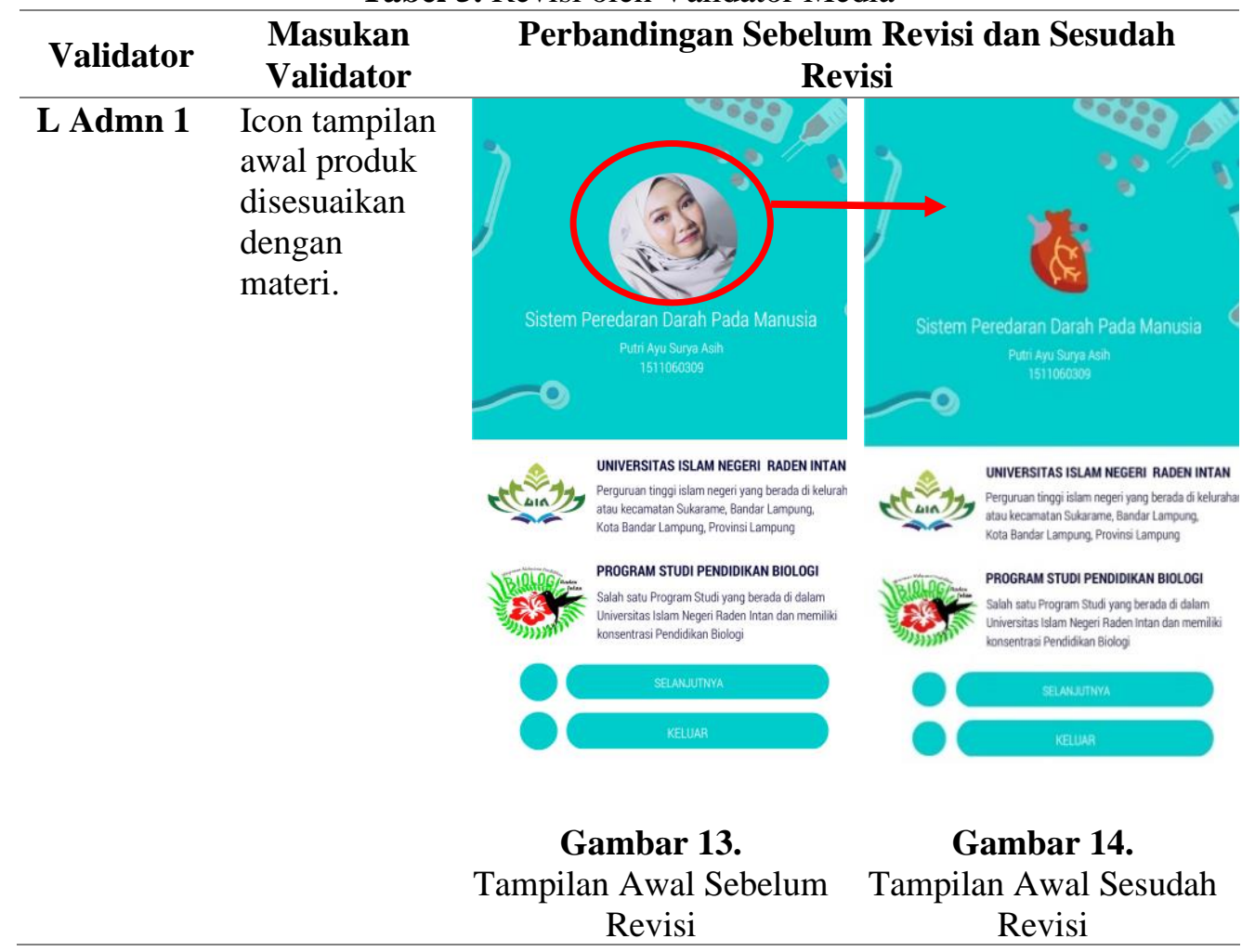

Tabel 6. Revisi oleh Validator Materi

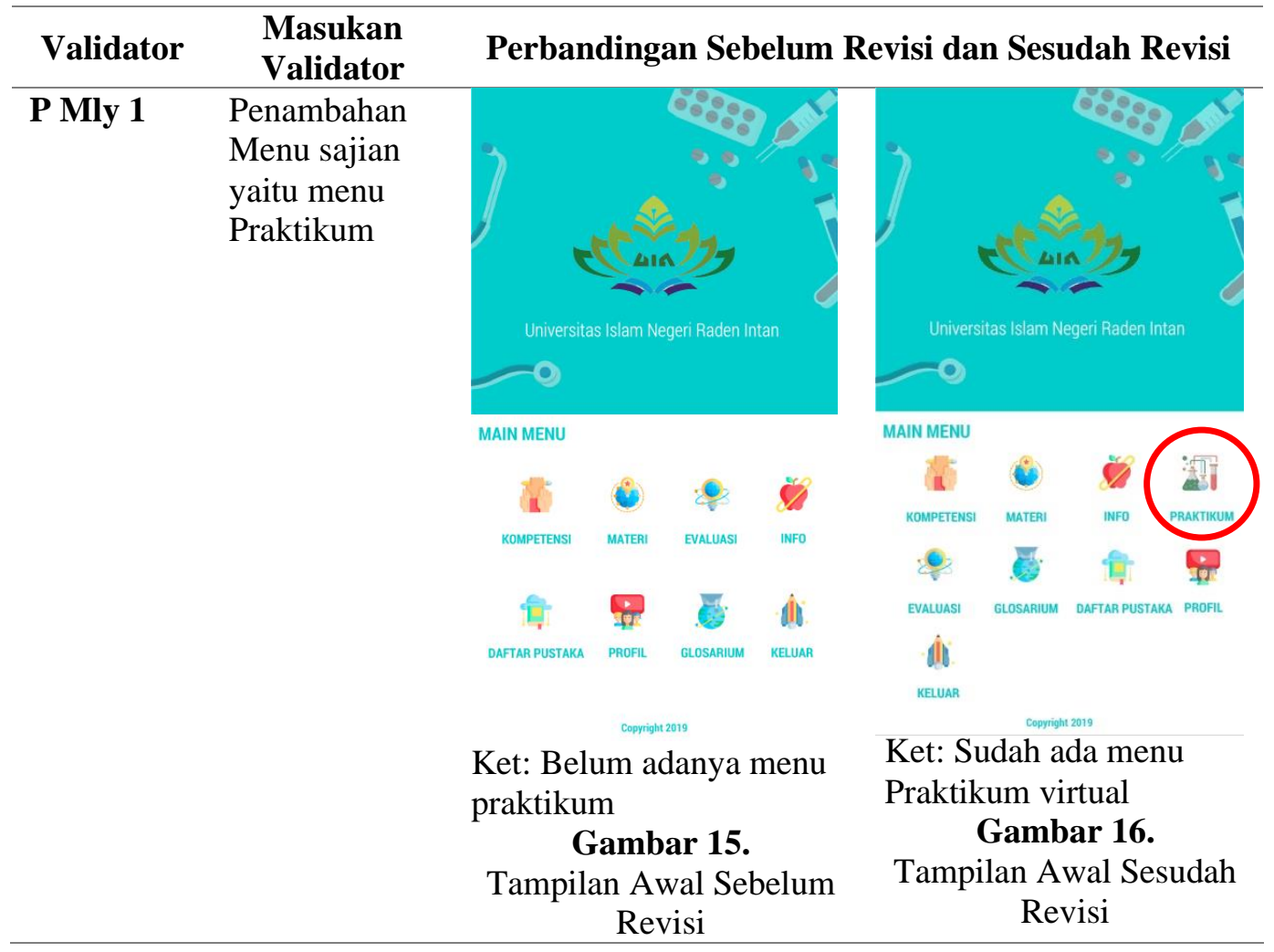




\begin{tabular}{|c|c|c|}
\hline Validator & $\begin{array}{l}\text { Masukan } \\
\text { Validator }\end{array}$ & Perbandingan Sebelum \\
\hline & $\begin{array}{l}\text { Penambahan } \\
\text { nilai-nilai } \\
\text { sains }\end{array}$ & 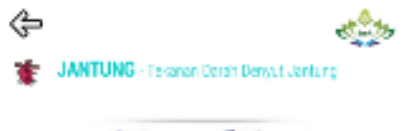 \\
\hline & & 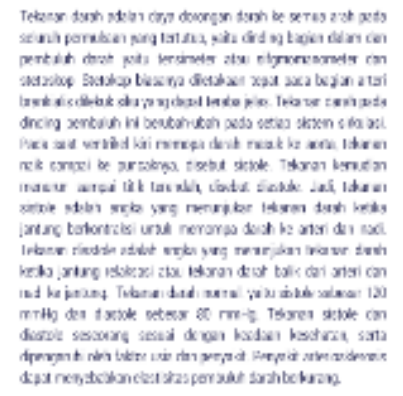 \\
\hline
\end{tabular}

Gambar 17.

Tampilan Isi Materi

Sebelum Revisi

\begin{tabular}{|c|c|c|}
\hline L Mr 2 & $\begin{array}{l}\text { Penambahan } \\
\text { gambar } \\
\text { mekanisme } \\
\text { darah }\end{array}$ & 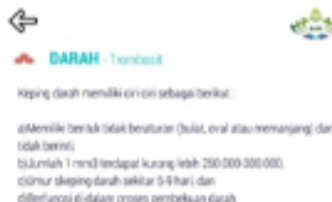 \\
\hline
\end{tabular}

Gambar 19.

Tampilan Awal Materi Sebelum Revisi
Tekanan darah adalah daya dorongan darah ke semua arah pada seluruh permukaan yang tertutup, yattu dinding bagian dalam dan pembuluh darah yatu tensimeter atau sifgmomanometer dan stetoskop. Stetokop blasannya diletakaan tepat pada bagian arter brankialis diliekuk siku yang dapat teraba jelas. Tekanan darah pad dinding pembuluh ini berubah-ubah pada setiap sistem sirkulas Pada saat ventrikel kiri memopa darah masuk ke aorla, lekanan nalk sampai ke puncaknya, disebut sistole. Tekanan kemudian menurun sampai titik terendah, disebut diastole. Jadi, tekanan sistole adalah angka yang menunjukan tekanan darah ketira jantung berkontraksi untuk memompa darah ke atteri dan nacich

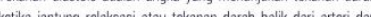

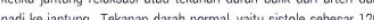

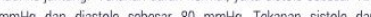

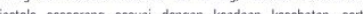

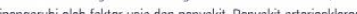

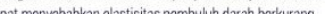

\section{LIHAT NILAI SAINS}

\section{Gambar 18.}

Tampilan Isi Materi Sesudah Revisi \&

$$
\approx \text { DARAH - Trombosit }
$$
+exty
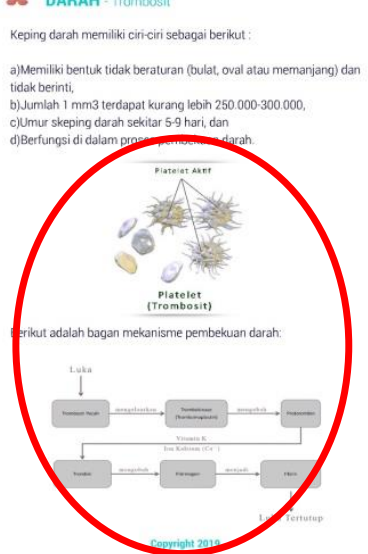

Gambar 20.

Tampilan Materi Sesudah Revisi 


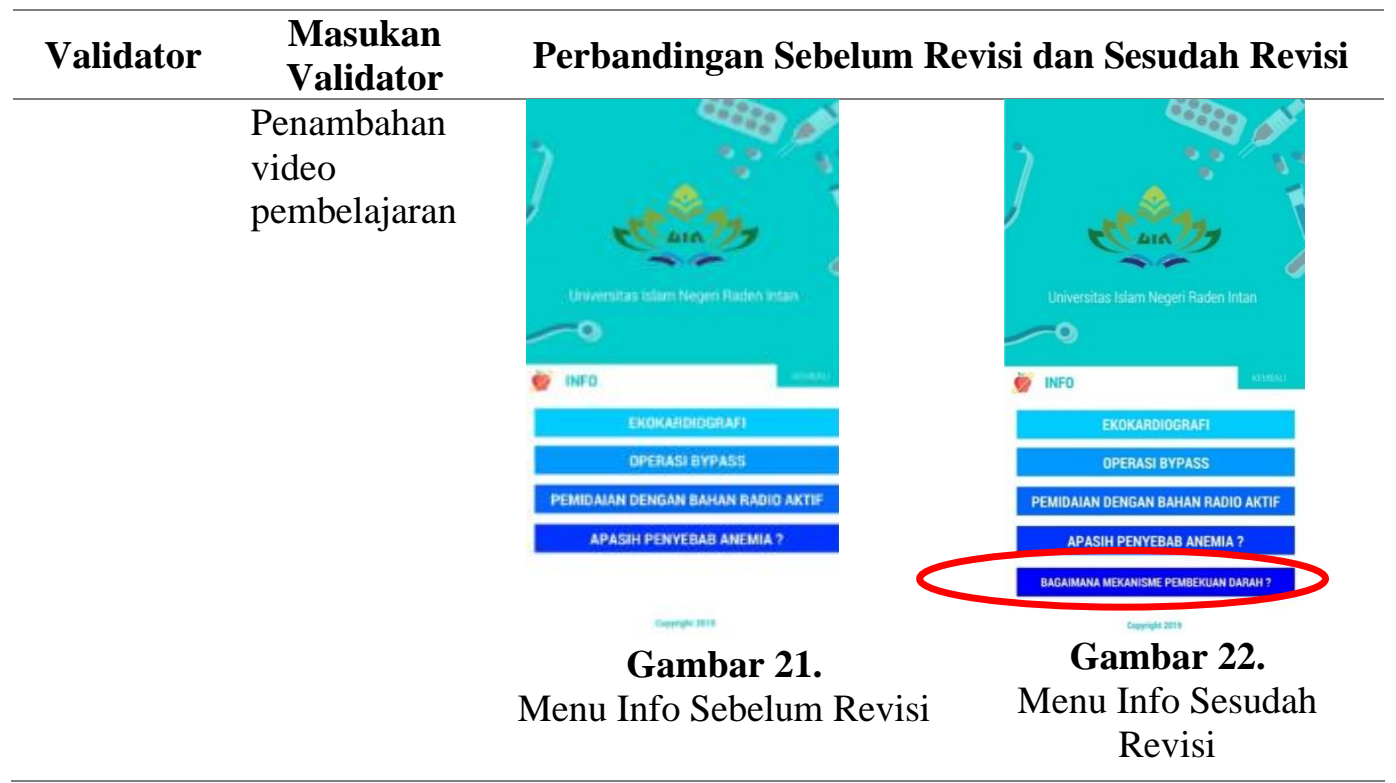

Tabel 7. Revisi oleh Validator Bahasa

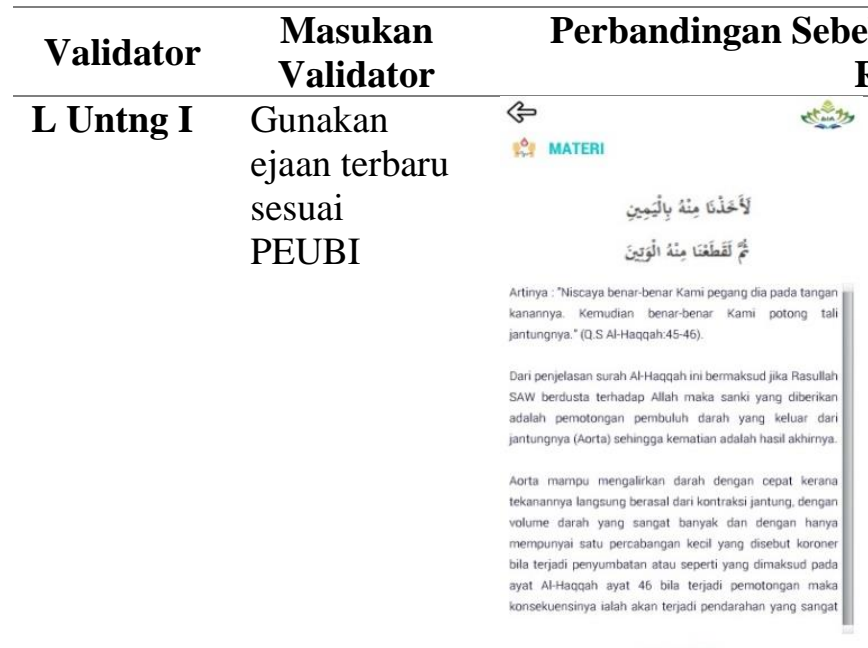

Gambar 4.18

Tampilan Awal Materi Sebelum Revisi
Revisi

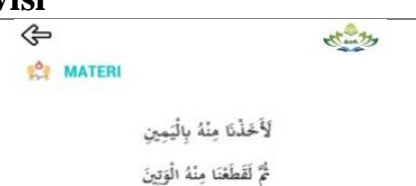

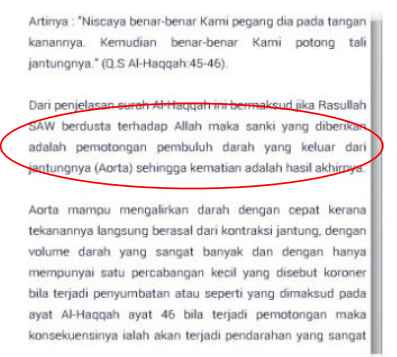

Gambar 4.19

Tampilan Materi

Sesudah Revisi

P N II Pengunaan
tanda baca $\begin{array}{ll}\text { yang } \\ \text { disesuaikan }\end{array}$

Gambar 4.20

Tampilan Menu Evaluasi Sebelum Revisi
Gambar 4.21

Tampilan Menu

Evaluasi Sebelum Revisi 
Tahapan keenam pengembangan yakni melakukan uji coba produk pendahuluan dengan melibatkkan sepuluh anak didik kelas XI sebagai responden awal terhadap multimedia yang dikembangkan.

Tabel 8. Hasil tanggapan peserta didik pada uji coba pendahuluan

\begin{tabular}{|c|c|c|c|c|c|}
\hline No & Responden & $\begin{array}{c}\text { Jumlah } \\
\text { Skor }\end{array}$ & $\begin{array}{c}\text { Skor } \\
\text { Maksimal }\end{array}$ & $\begin{array}{c}\text { Persentase } \\
(\%)\end{array}$ & Kriteria \\
\hline 1. & Rl & 100 & 128 & $78,1 \%$ & Layak \\
\hline 2. & R2 & 105 & 128 & $82,0 \%$ & Sangat Layak \\
\hline 3. & $\mathrm{R} 3$ & 96 & 128 & $75 \%$ & Layak \\
\hline 4. & R4 & 99 & 128 & $77,3 \%$ & Layak \\
\hline 5. & R5 & 94 & 128 & $73,4 \%$ & Layak \\
\hline 6. & R6 & 97 & 128 & $75,7 \%$ & Layak \\
\hline 7. & R7 & 92 & 128 & $71,8 \%$ & Layak \\
\hline 8. & R8 & 98 & 128 & $76,5 \%$ & Layak \\
\hline 9. & R9 & 96 & 128 & $75 \%$ & Layak \\
\hline 10. & R10 & 98 & 128 & $76,5 \%$ & Layak \\
\hline \multicolumn{2}{|c|}{ Total Jumlah Skor } & \multicolumn{4}{|c|}{975} \\
\hline \multicolumn{2}{|c|}{ Jumlah Skor } & \multicolumn{4}{|c|}{1280} \\
\hline \multicolumn{2}{|c|}{ Persentase (\%) } & \multicolumn{4}{|c|}{$76,1 \%$} \\
\hline \multicolumn{2}{|c|}{ Kriteria } & \multicolumn{4}{|c|}{ Layak } \\
\hline
\end{tabular}

Tahapan ketujuh yakni revisi produk, pada Tebel 8 menjelaskan bahwa produk telah layak di uji cobakan ke tahapan delapan yaitu uji efektivitas atau uji skala luas yang melibatkan 60 peserta didik kelas XI yang terbagi menjadi dua kelas. Kelas kontrol adalah kelas yang tidak diberi perlakuan menggunakan produk melainkan dengan media persentasi yang masih bersifat konvensional yang terdiri dari 30 responden dan kelas eksperimen adalah kelas yang diberi perlakuan menggunakan produk multimedia interaktif terintegrasi nilai sains yang terdiri dari 30 responden, hal ini dilakukan untuk melihat keefektifan multimedia interaktif yang dikembangkan melalui pemberian soal (Tabel 9) hasilnya dapat dilihat melalui perolehan hasil uji $\mathrm{t}$ Independent Tabel 13.

Tabel 9. Rata-rata Nilai Kemampuan Berpikir Kritis Peserta Didik Kelas Eksperimen dan Kontrol

\begin{tabular}{cccccc}
\hline & $\begin{array}{c}\text { Jumlah } \\
\text { Peserta } \\
\text { Didik }\end{array}$ & \multicolumn{2}{c}{ Nilai Rata-Rata } & N-Gain & Kriteria \\
& 30 & 45,50 & 80,83 & O,66 & Sedang \\
\hline $\begin{array}{c}\text { Kelas } \\
\text { Eksperimen }\end{array}$ & & & & & \\
\hline $\begin{array}{c}\text { Kelas } \\
\text { Kontrol }\end{array}$ & 30 & 41,83 & 59,33 & 0,29 & Rendah \\
\hline
\end{tabular}

Tabel 10. Uji Normalitas Kelas Kontrol

\begin{tabular}{ccccc}
\hline $\begin{array}{c}\text { Kelas } \\
\text { Kontrol }\end{array}$ & $\mathbf{L}_{\text {hitung }}$ & $\mathbf{L}_{\text {tabel }}$ & Indeks & Kesimpulan \\
\hline $\begin{array}{c}\text { XI Mipa } \\
\mathbf{6}\end{array}$ & 0,132 & 0,161 & $\mathrm{~L}_{\text {hitung }}<$ & $\mathrm{H}_{\mathrm{o}}$ diterima \\
& & & $\mathrm{L}_{\text {tabel }}$ & $\begin{array}{c}\text { (data } \\
\text { berdistribusi } \\
\text { normal) }\end{array}$ \\
\hline
\end{tabular}


Tabel 11. Uji Normalitas Kelas Eksperimen

\begin{tabular}{ccccc}
\hline $\begin{array}{c}\text { Kelas } \\
\text { Eksperimen }\end{array}$ & $\mathbf{L}_{\text {hitung }}$ & $\mathbf{L}_{\text {tabel }}$ & Indeks & Kesimpulan \\
\hline XI Mipa 4 & 0,068 & 0,161 & L hitung $<\mathrm{L}_{\text {tabel }}$ & $\begin{array}{c}\mathrm{H}_{\mathrm{o}} \text { diterima } \\
\text { (data } \\
\text { berdistribusi } \\
\text { normal) }\end{array}$ \\
\hline
\end{tabular}

Tabel 12. Uji Homogenitas Kelas Kontrol \& Eksperimen Terhadap Kemampuan Berpikir Kritis

\begin{tabular}{lccl}
\hline \multicolumn{1}{c}{ Jenis Tes } & $\mathbf{F}_{\text {hitung }}$ & $\mathbf{F}_{\text {tabel }}$ & Kesimpulan \\
\hline $\begin{array}{l}\text { Pretest dan posttest } \\
\text { kemampuan } \\
\text { berpikir kritis kelas }\end{array}$ & 0,27 & 3,34 & $\begin{array}{l}\text { Data bersifat } \\
\text { homogen }\end{array}$ \\
$\begin{array}{l}\text { kontrol dan } \\
\text { eksperimen }\end{array}$ & & & \\
\hline
\end{tabular}

Tabel 13. Hasil Perhitungan Uji t Independent

\begin{tabular}{ccc}
\hline $\mathbf{t}_{\text {hitung }}$ & $\mathbf{t}_{\text {tabel }}$ & Kesimpulan \\
\hline $\mathbf{7 , 9 5}$ & 1,70 & $\mathrm{H}_{1}$ diterima \\
\hline
\end{tabular}

\section{PEMBAHASAN}

Multimedia interaktif terintegrasi nilai sains pada materi sistem peredaran darah manusia yang dikembangkan dikemas berupa aplikasi yang dijalankan atau diinstal di smartphone android. Pengembangan media pembelajaran ini dimaksudkan untuk mempermudah memperoleh informasi serta materi sehingga peserta didik lebih mudah dapat memahami isi penjelasan yang disampaikan oleh pendidik. Penggunaan multimedia membuat pembelajaran lebih menarik dan bermakna seperti halnya pendapat (Arfi Setiawan et al, 2016) dalam jurnalnya yang menyatakan bahwa multimedia yang mengintegrasikan objek media berupa video, animasi, teks, dan suara dapat mewakili menyampaikan informasi yang memiliki potensi dalam membantu mencapai tujuan pembelajaran. Pada multimedia interaktif terintegrasi nilai sains ini mudah digunakan karena bisa diakses bebas dalam genggaman pemakainya melalui perangkat smartphone android dalam mode offline. Kelebihan lain dari produk multimedia interaktif ini berisi penjelasan materi berupa teks yang memuat gambar, video belajar sehingga membantu anak didik dalam pemahaman materi, bukan hanya itu penjelasan materi juga dilengkapi dengan nilai- nilai sains yang disesuaikan dengan materi. Produk ini dilengkapi dengan praktikum virtual dan soal-soal evaluasi yang telah disesuaikan dengan indikator kemampuan berpikir kritis, sehingga dapat membantu peserta didik dalam merangsang dan meningkatkan kemampuan berpikir kritis sehingga mampu menerapkannya dalam belajar maupun dalam kegiatan seharihari.

Pendapat (Adita et al, 2016), menyatakan bahwa pemanfaatan teknologi dalam kegiatan belajar dapat merangsang dan mempermudah siswa dalam meningkatkan pemahaman materi. Multimedia interaktif yang dikemas dengan menarik dan berbasis android sehingga membuat proses pembelajaran lebih efektif. Hal ini serupa dengan pendapat (Herpratiwi, 2016), bahwa multimedia yang digunakan dalam pembelajaran dapat menyalurkan pesan yang mampu merangsang pikiran, perasaan, perhatian dan kemauan belajar sehingga secara sengaja proses belajar terjadi, bertujuan dan terkendali. Melalui multimedia interaktif, peserta didik dapat mengeksplorasi pelajaran dengan mandiri, menemukan serta menyusun sendiri pengetahuan yang diperoleh, serta lebih mudah memulai, mengakhiri pelajaran dan mengulang isi materi yang belum dipahami (Sari et al, $\underline{2016}$ ). 
Dalam menciptakan produk multimedia interaktif yang valid, metode penelitian yang digunakan adalah penelitian dan pengembangan (R\&D) (Sugiyono, 2017) yang disesuaikan dari model penelitian Borg \& Gall yang dibatasi sampai sembilan tahap pengembangan. Berlandasan pendapat Borg and Gall bahwa pada tahapan pengembangan makin disederhanakan tetapi bukan menghilangkan sedikitpun arti nilai penelitian pengembangan yang dilakukan. Peneliti menyederhanakan tahapan penelitian pengembangan multimedia interaktif berdasarkan pada rumusan masalah yang telah dirumuskan adalah untuk mengetahui keefektifan multimedia interaktif yang dikembangkan, selain itu, karena memperkirakan waktu dan anggaran yang dimiliki peneliti.

Hasil studi lapangan menunjukkan bahwa sekolah sudah menyediakan teknologi sebagai sarana pembelajaran (proyektor dan laptop) namun belum digunakan secara berkala. Martopan Abdullah mengatakan fasilitas sekolah yang memadai akan mempengaruhi proses belajar yang efektif dan membantu meningkatkan keberhasilan pendidikan disekolah selain guru (Abdullah et al, 2018). Hasil studi lapangan juga menunjukan bahwa mayoritas peserta didik telah menggunakan smartphone namun belum digunakan sebagai media pembelajaran. Analisis data yang dilakukan websindo dari situs We are social menunjukan pada tahun 2019 pengguna Mobile (smartphone) di Indonesia mencapai 355,5 juta hasil ini memperlihatkan peredaran ponsel pintar lebih banyak dibandingkan total penduduk Indonesia (268,2 juta) (Websindo, 2019). Perserta didik berpendapat menginginkan media pembelajaran berbasis mobile menggunakan smartphone agar proses pembelajaran lebih menarik dan mudah dalam memahami pembelajaran. Hal ini sejalan dengan pendapat Azhar Arsyad, penggunaan media dalam proses pembelajaran mampu meningkatkan pemahaman, minat, mempermudah memperoleh pengetahuan atau informasi dan memotivasi peserta didik (Arsyad, 2016).

Proses pengembangan desain aplikasi multimedia interaktif digunakan software untuk mendukung pembuatan produk diantranya adobe flash CS6, corell draw x6, photoshop cc 2017, dan adobe animate 2016. Selanjutnya menentukan unsur-unsur yang akan di tampilkan dalam produk multimedia interaktif, unsurnya berupa teks, gambar, video, dan desain icon-icon lain yang mendukung pengembangan produk. Lalu terbentuklah hasil gambaran tampilan produk (storyborad) multimedia interaktif terintegrasi nilai sains terhadap kemampuan berpikir kritis ini yang berisi materi yang disusun berdasarkan Kompetensi dasar dan indikator pembelajaran yang ada dalam silabus kurikulum 2013. Produk ini dilengkapi video, gambar sebagai penjelas materi pembelajaran serta menu-menu sajian lainnya seperti praktikum virtual, info biologi, evaluasi, glosarium, daftar putaka dan profil pengembang produk.

Penilaian validasi produk ini dilakukan oleh ahli media, ahli materi dan ahli bahasa menggunakan instrumen berupa angket skala likert yang berisikan pertanya positif negatife yakni berupa pilihan 4 skala jawaban yaitu Sangat Layak (SL), Layak (L), Tidak Layak (TL), dan Sangat Tidak Layak (STL). Penggunaan skala 4 agar dapat melihat perbedaan sikap dalam memilih jawaban sehingga tidak ada yang bersifat netral yang membuat pertanyaan akan dijawab secara objektif (Putro Widoyoko, 2012). Tahapan validasi produk pada penelitian ini dengan menggunakan dua validator ahli atau lebih pada setiap aspek guna sebagai perbandingan. Hal ini sejalan dengan riset yang dilakukan sebelumnya oleh Achmad Buchori et. al (2019), dan Thomas Adi Tri Nugroho (2018). Validasi produk dilaksanakan oleh dosen ahli bidang dari kalangan dosen UIN Raden Intan Lampung, Universitas Aisyah Pringsewu, dan dosen Dian Cipta Cendikia Pringsewu. Eetiap ahli memiliki perbedaan kriteria penilaian, ahli media melakukan penilaian pada bagian tampilan dan pemprograman aplikasi, ahli materi memberikan penilaian bagaian materi dan penyajian materi agar sesuai dengan kurikulum yang berlaku, dan ahli bahasa memberikan penilaian berkenaan dengan kebahasaan dan penyajian berdasarkan aturan PEUBI yang berlaku.

Hasil penilaian ahli media memperoleh keseluruhan nilai dengan persentase rata-rata total sebesar $87,10 \%$, ahli materi secara keseluruhan memperoleh persentase rata-rata total sebesar $83,00 \%$ dan hasil keseluruhan persentase rata-rata total penilaian ahli bahasa 
sebesar $83,08 \%$ yang artinya produk dinyatakan sangat layak.

Berdasarkan hasil uji normalitas kelas kontrol didapat hasil $\mathrm{L}_{\text {hitung }} 0,132<\mathrm{L}_{\text {tabel }} 0,161$ dengan hipotesis $\mathrm{H}_{0}$ diterima, sehingga dapat disimpulkan bahwa data berdistribusi normal. Hasil uji normalitas kelas eksperimen didapatkan hasil $\mathrm{L}_{\text {hitung }} 0,068<\mathrm{L}_{\text {tabel }}$ 0,161dengan hipotesis $\mathrm{H}_{0}$ dierima, sehingga dapat disimpulkan bahwa data berdistribusi normal. Selanjutnya dilakukan uji homogenitas, hasil dari perhitungan didapatkan $\mathrm{F}_{\text {hitung }} 0,27<$ $\mathrm{F}_{\text {tabel }} 1,86$ dengan $\mathrm{H}_{0}$ diterima sehingga dapat disimpulkan bahwa data tersebut bersifat homogen.

Selanjutnya hasil perhitungan uji $\mathrm{t}$

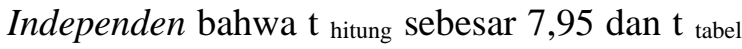
1,70. Sehingga disimpulkan bahwa $t_{\text {hitung }}>t_{\text {tabel }}$ dengan $\mathrm{H}_{1}$ diterima dan $\mathrm{H}_{0}$ ditolak, yang artinya penggunaan multimedia interaktif terintegrasi nilai sains berpengaruh terhadap peningkatan kemampuan berpikir kritis peseta didik dibandingkan dengan media pembelajaran konvensional. Kemudian hasil perhitungan ratarata $N$-Gain kelas eksperimen didapat nilai sebesar 0,66 sedangkan rata-rata $N$-Gain kelas kontrol sebesar 0,29 dari hasil tersebut dapat disimpulkan bahwa penerapan multimedia interaktif lebih efektif daripada yang tidak. Dan hasil respon 30 peserta didik pada multimedia interaktif nilai sais persentasenya 85,33\% berarti Sangat Layak. Seperti yang telah diketahui bahwa hasil uji coba penggunaan media memperoleh respon yang sangat baik sehingga produk layak dijadikan sebagai media pembelajaran serta menjadi solusi dalam membantu meningkatkan kemampuan berpikir kritis peserta didik. Penilaian yang sangat baik mengindikasikan bahwa multimedia interaktif yang dikembangkan telah sesuai dengan karakteristik materi serta sesuai kondisi dan kebutuhan dalam kegiatan pembelajaran (Septian et al, 2019).

Dalam pengunaan multimedia interaktif dalam pembelajaran yang memadukan berbagai unsur berupa teks, gambar, video, maupun animasi mampu membuat kualitas proses pembelajaran dan hasil menjadi lebih baik seperti Praheto \& Biya Ebi et al (2017), menjelaskan bahwa penggunaan multimedia dapat mengembangkan kemampuan indera dengan menyajikan informasi yang dapat dilihat, didengar, dan dilakukan, sehingga multimedia sangat efektif dijadikan alat yang lengkap dalam proses pengajaran dan pembelajaran yang menarik perhatian serta minat peserta didik.

\section{SIMPULAN}

Berdasarkan hasil penelitian dan pembahasan yang telah diuraikan dapat disimpulkan bahwa multimedia interaktif terintegrasi nilai sains sangat layak digunakan sebagai media pembelajaran biologi berdasarkan penilaian oleh ahli media sebesar $87,10 \%$, ahli materi sebesar $83,00 \%$, dan ahli bahasa sebesar $83,08 \%$ dengan kriteria "Sangat Layak". Dan berdasarkan hasil nilai $N$-Gain pada kelas eskperimen sebesar 0,66 dengan kategori sedang, sedangkan kelas kontrol sebesar 0,29 dengan kategori rendah, artinya nilai $\mathrm{N}$-Gain kelas eksperimen lebih besar dibandingkan kelas kontrol yang artinya bahwa multimedia interaktif terintegrasi nilai sains lebih efektif digunakan sebagai solusi peningkatan kemampuan berpikir kritis peserta didik. Produk yang dikembangkan dapat digunakan sebagai acuan pembuatan multimedia interaktif serupa dengan lebih menarik lagi dengan berbagai macam materi dalam satu aplikasi. Aplikasi dapat diakses di: https://drive.google.com/drive/folders/1-9GIizWhp6h1c1js9wRq2gLaft9i Tn

\section{REFERENSI}

Abdullah, Martopan, and Universitas Trunajaya Bontang. (2018). Pengaruh Fasilitas Sekolah Dan Motivasi Guru Terhadap Efektivitas Proses Mengajar Di. Vol. 6, no. 2, pp. 165-75.

Achmad Buchori. (2019). Pengembangan Multimedia Interaktif Dengan Pendekatan Kontekstual Untuk Meningkatkan Pemecahan Masalah Kemampuan Matematika. Vol. 6, no. 1, pp. 104-15.

Adi Tri Nugroho, Thomas. (2018). "Pengembangan Multimedia Pembelajaran Interaktif Berbasis Mobile Untuk Meningkatkan Kemampuan Berpikir Kritis Dan Keterampilan Proses Siswa Kelas IV." Tesis.

Adita, Arum, and Teguh Julianto. (2016). Penyusunan Virtual Laboratory Sebagai Media Pembelajaran Biologi, pp. 69-73.

Anggoro, Bambang Sri, and Hawanii. Haka, Nukhbatul Bidayati. (2019). Biodik: 
Quagga: Jurnal Pendidikan dan Biologi

Volume 13, Nomor 1, Januari 2021, pp.1-13

Jurnal Ilmiah Pendidikan Biologi The Development of Al-Qur' an Hadith Based on Biology Subject for Class X Student High Scholl / MA Level Pengembangan Majalah Biologi Berbasis Al-Qur 'an Hadist Pada Mata Pelajaran. Vol. 5, no. 2, 2019, pp. 164-72.

Arfi Setiawan, Mohammad. (2016). Pengaruh Bahan Ajar Multimedia Terhadap Matakuliah Kimia Organik I. no. 2011, pp. 746-51.

Arsyad, Azhar. (2017). Media Pembelajaran. Rajawali Pers.

Basith, Abdul. (2018). Pengembangan Media Pembelajaaran Interaktif Fluida Statis Dalam Perspektif Al-Quran Menggunakan Macromedia Flash Development Of Static Fluid Interactive Learning Media In The Al-Quran Perspective Using Macromedia. Vol. 01, pp. 217-25.

Hariyadi. (2019). Paradigma Pendidikan Dalam Menghadapi Revolusi Industri 4.0.

Herpratiwi, Noni Heriawati. (2016). Pengembangan Multimedia Interaktif Untuk Pembelajaran Management File Microsoft Word Siswa Kelas X SMA Di Kalianda. pp. 1-15.

Indonesia Digital .(2019). Tinjauan Umum, (On-Line) Tersedia Di: Https://Websindo.Com/Indonesia-Digital2019-Tinjauan-Umum/.

Manek, Agustinus Hale, et al. (2019). Pengaruh Model Spasial Based Learning Terhadap Kemampuan Berpikir Kritis Siswa. no. 1, pp. $440-46$.

Nukhbatul Bidayati Haka, Suhanda. (2018). "Pengembangan Media Komik Manga Biologi Berbasis Android Untuk Peserta Didik Kelas XI Di Tingkat SMA/MA." Journal Of Biology Education IAIN Kudus.

Oktavian, Riskey, et al (2020). Efektivitas
p-ISSN 1907-3089, e-ISSN2651-5869

https://journal.uniku.ac.id/index.php/quagga

Pembelajaran Daring Terintegrasi Di Era Pendidikan 4.0. Vol. 20, no. 2, 2020, pp. 129-35.

Praheto, Biya Ebi, et al. (2017). Peran Multimedia Intraktif Dalam Pembelajaran Keterampilan Berbahasa Indonesia Di PGSD. pp. 173-77.

Putro Widoyoko, Eko. (2012). Teknik Penyusunan Instrumen Penelitian. Pusat Belajar, pp. 102-06.

Sari, Liza Yulia, and Diana Susanti. (2016). Uji Efektivitas Media Pembelajaran Interaktif Berorientasi Konstruktivisme Pada Materi Neurulasi Untuk Perkuliahan Perkembangan Hewan. Vol. II, no. 1, pp. 158-64.

Septian, Damar, et al. (2019). Pengaruh Multimedia Interaktif Berbasis Learning Cycle Terhadap Hasil Belajar Siswa. Vol. 2, no. 1, pp. 6-16.

Sri Anggoro, Bambang. (2015). "Pengembangan Modul Matematika Dengan Strategi Problem Solving Untuk Mengukur Tingkat Kemampuan Berpikir Kreatif Matematis Siswa." Al-Jabar: Jurnal Pendidikan Matematika, vol. 6, no. 2, pp. 122-23.

Sugiyono. (2017). Metode Penelitian Pendidikan Pendekatan Kuantitatif, Kualitatif, Dan RnD. Bandung: ALFABETA.

Sundayana, Rostina. (2014). Statistika Penelitian Pendidikan. Bandung: ALFABETA.

Yudianto. (2005). Manajemen Alam Sumber Pendidikan Nilai. Mughani Sejahtera. 